\title{
Numerical Simulation of the Stress Field in Repeated Mining of Coal Seams Based on In Situ Stress Measurement
}

\author{
Donghui Yang $\mathbb{D}^{\mathbb{D}}$, Bohu Yang, Zhaoheng Lv, Yongming Li, Hongming Cheng, \\ and Zhangxuan Ning \\ School of Coal Engineering, Shanxi Datong University, Datong 037003, China \\ Correspondence should be addressed to Donghui Yang; ydhname@163.com
}

Received 9 August 2021; Accepted 27 September 2021; Published 9 November 2021

Academic Editor: Qiuhong Wu

Copyright ( 2021 Donghui Yang et al. This is an open access article distributed under the Creative Commons Attribution License, which permits unrestricted use, distribution, and reproduction in any medium, provided the original work is properly cited.

\begin{abstract}
We established an evaluation index of the rock mass stress state for underground coal mines using the strength-stress ratio based on the measured in situ stress and the generalized Hoek-Brown strength criterion. Three in situ stress states, $\sigma_{c m} / \sigma_{1 m}<1.4$ (high), $1.4<\sigma_{c m} / \sigma_{1 m}<3.6$ (medium), and $\sigma_{c m} / \sigma_{1 m}>3.6$ (low), were established based on the value of the unconfined compressive strength $\left(\sigma_{c m}\right)$ and the maximum principal stress of the rock mass $\left(\sigma_{1 m}\right)$. This index classifies the Burtai mine as a medium-high in situ stress field, which is in agreement with the on-site situation, establishing the reliability of the index. The working face was a three-dimensional geological model based on the log sheets. The initial conditions for the model were determined using the combined measurements of the in situ stress regression model. We performed numerical simulations of the roof stress field distribution under repeated mining. Mining the overlying coal seam leads to significant variation in the value and direction of the main roof, $\sigma_{1}$, within the range of the front abutment pressure under the pillar and gob. Along the main roof strike direction, $\sigma_{1}$ under the pillar is 1.5 times that under the gob, and the $\sigma_{1}$ direction under the pillar is deflected by $5^{\circ}$, which is $30^{\circ}$ smaller than that under the gob. This provides a reference for optimized underground coal mining.
\end{abstract}

\section{Introduction}

The combination of in situ stress and mining stress in underground coal mines forms a mining stress field. This stress field is directly related to the stress state of the overlying strata of the coal seam and the structural movement characteristics, and it affects the safe mining of the working face. The cause of in situ stress is complex, and it has an irregular distribution. It is affected by several factors, including depth, topography, structure, lithology, and residual stress. Hast [1] studied the distribution of in situ stress in different regions of western European countries, such as Norway and Sweden, based on which Stephansson et al. [2] established a regional in situ stress database in 1969. Brown and Hoek [3] analyzed the results of in situ stress in the shallow crust at a depth of $3 \mathrm{~km}$ in 1978 . Haimson [4] summarized the in situ stress distribution in the United States at a depth of $0-5 \mathrm{~km}$ in 1980. Sheorey [5] proposed a crustal stress calculation model suitable for $138.87 \mathrm{~m} \sim 33.73 \mathrm{~km}$. The World Stress Map (WSM) project [6] compiles the direction of the maximum horizontal principal stress $\left(\sigma_{H}\right)$. WSM 2016 has 42,870 data records, which is double that of WSM 2008. Statistical studies on the distribution of crustal stress fields have been conducted in mainland China [7-12]. Kang et al. [13] compiled 1,357 in situ stress data in the "Database of in situ stress in underground coal mines in China," and observed three stress field distributions: $\sigma_{H}>\sigma_{h}>\sigma_{v} \quad(<150 \mathrm{~m}), \quad \sigma_{H}>\sigma_{v}>\sigma_{h} \quad(150-1000 \mathrm{~m}), \quad$ and $\sigma_{v}>\sigma_{H}>\sigma_{h}(>1000 \mathrm{~m})$. Yang [14] investigated the in situ stress in 26 groups of the northern Ordos Basin, China, and analyzed the principal stress distribution with depth, $\sigma_{H}=5.3367 \pm 0.023$ $H$, correlation coefficient $R^{2}=0.94$, and $\sigma_{h}=0.6559 \pm 0.017 \mathrm{H}$, $R^{2}=0.55$; the dominant orientation of $\sigma_{H}$ is the NEE. However, it cannot be used for establishing mine-scale engineering practice guidelines due to the variation in survey locations, and therefore, area-specific studies on in situ stress measurement and application are required.

The in situ stress state and the strength of the intact rock mass are essential for the stability of underground coal mines. 
At present, the empirical method, the strength-stress ratio method, the stress ratio method, and the geological marker method are used for evaluating the in situ stress state. Although $20 \mathrm{MPa}$ is the typical high-stress standard, Yu et al. [15] proposed a standard of $0-10 \mathrm{MPa}$ (low stress), $10-18 \mathrm{MPa}$ (medium stress), $18-30 \mathrm{MPa}$ (high stress), and greater than $30 \mathrm{MPa}$ (superhigh stress). The strength-stress ratio method is the most widely used method [16, 17], but it lacks a unified standard. The Sheorey model [5] has been widely recognized in engineering design since it can predict horizontal stress and address the discrete stress values. The evaluation parameters include weathered rock mass or shallow surface engineering areas, which do not conform to the actual condition of coal mines [18-22]; therefore, the stress state evaluation indicators based on in situ stress data are required.

The strength-stress ratio method was used to establish the evaluation index for the stress state of the mine rock mass based on the in situ stress measurement through Kaiser effect and the generalized Hoek-Brown rock mass strength criterion, and a preliminary engineering verification was carried out. A refined geological model for the stratum occurrence conditions in the Burtai mine was established with 42\# coal seam mining combined with the measured in situ stress regression model. The roof stress field of the working face under repeated mining conditions provided a reference for optimizing the mining plan in the Burtai mine and provided the guidelines for mines under similar conditions.

\section{In Situ Stress Measurement in the Study Area}

The Burtai mine is an extra-large mine in the Shendong mining area in China with a designed production capacity of $20 \mathrm{Mt} / \mathrm{a}$ and a service life of 71.9 a. Currently, 22\# coal seam, having a thickness between 0.82 and $5.80 \mathrm{~m}$ and an average thickness of $2.52 \mathrm{~m}$, and 42 \# coal seam, with thickness between 0.90 and $7.68 \mathrm{~m}$ and $6.50 \mathrm{~m}$ average thickness of the coal seam, are mined in the entire area. The coal seam has a simple structure with a stable layer, and it is a low-gas mine. The upper and lower coal seams of 22\# and 42\# are mined at the same time. With the increase in mine depth beyond $400 \mathrm{~m}$, in situ stress becomes prominent due to increased mining intensity. Repeated mining causes severe disturbance with complex breaking characteristics of the overlying rock. For example, roof sinks and the bottom heaves were observed in the return roadway along the 22103 working face, resulting in the roadway being re-dug twice. The slab was damaged in the $0.2-1.5 \mathrm{~m}$ depth along the 42105 working face because of mechanized mining and poor caving technology, and roof weighting over a large area was observed. The above phenomena are inseparable from the in situ stress field.

Yang $[14,23,24]$ established an in situ stress test based on the Kaiser effect of a borehole core and analyzed the in situ stress distribution in and around the boreholes of the Burtai mine, as shown in Figure 1.

The principal stress values are discrete but increase with an increase in depth (Figure 1(a)) and the fitting equations are as follows (equation (1)). Three stress field distributions are present: $\sigma_{H}>\sigma_{h}>\sigma_{v}(<172 \mathrm{~m}), \sigma_{H}>\sigma_{v}>\sigma_{h}(172-800 \mathrm{~m})$, and $\sigma_{v}>\sigma_{H}>\sigma_{h}(>800 \mathrm{~m})$.

$$
\left.\begin{array}{l}
\sigma_{H}=2.0386+0.0241 \times H \\
\sigma_{h}=1.2091+0.0172 \times H \\
\sigma_{v}=-0.5257+0.0273 \times H
\end{array}\right\} .
$$

In Figure 1(b), the variation of $k\left(\left(\sigma_{H}+\sigma_{h}\right) / 2 \sigma_{v}\right)$ with depth is shown in equation (2) and compared with the $k$ envelope (equation (3)) obtained by Brown and Hoek. The variation is similar to the progressive value of the inner envelope, and the $k$ range reduces with an increase in depth (at $350 \mathrm{~m}, k=0.98$ ).

$$
\left.\begin{array}{l}
k=\frac{126}{H}+0.625 \\
\frac{35}{H}+0.285<k<\frac{350}{H}+0.6
\end{array}\right\},
$$

\section{Evaluation of the Stress State in Underground Coal Mining}

3.1. Evaluation Index of the Stress State. The rock mass stress state affects the rock mass stability and includes in situ stress, rock mass strength, and rock mass structural quality. Several classification systems have been developed for rock mass. The rock quality designation (RQD), proposed by Deere in 1964 [25], is one of the simplest systems of rock mass classification. The rock mass rating system (RMR) [26] and tunneling quality index (Q system) [27] are the most widely utilized rock mass classification schemes, and they have been widely adopted in the mining industry. The Hoek-Brown strength criterion, developed in 1980 [28-31], can account for the nonlinear behavior of the ultimate principal stresses when a rock mass fails and describes the influence of the rock mass structure and stress state on its strength. The parameters can be obtained qualitatively or quantitatively using conventional mechanical tests and field structure descriptions. The associated geological strength index (GSI) is widely used for estimating the strength and deformation of heavily jointed rock masses. The stress-based failure criteria developed by Coulomb, Mohr, and Hoek and Brown are extensively applied in rock mechanics. The Hoek-Brown strength criterion has undergone several modifications, and the final version (2018) is given by the following equation and described by Hoek and Brown in 2019:

$$
\sigma_{1}=\sigma_{3}+\sigma_{c i}\left(m_{b} \frac{\sigma_{3}}{\sigma_{c i}}+s\right)^{\alpha}
$$

where $m_{b}, s$, and $\alpha$ are the rock mass material constants, given by 


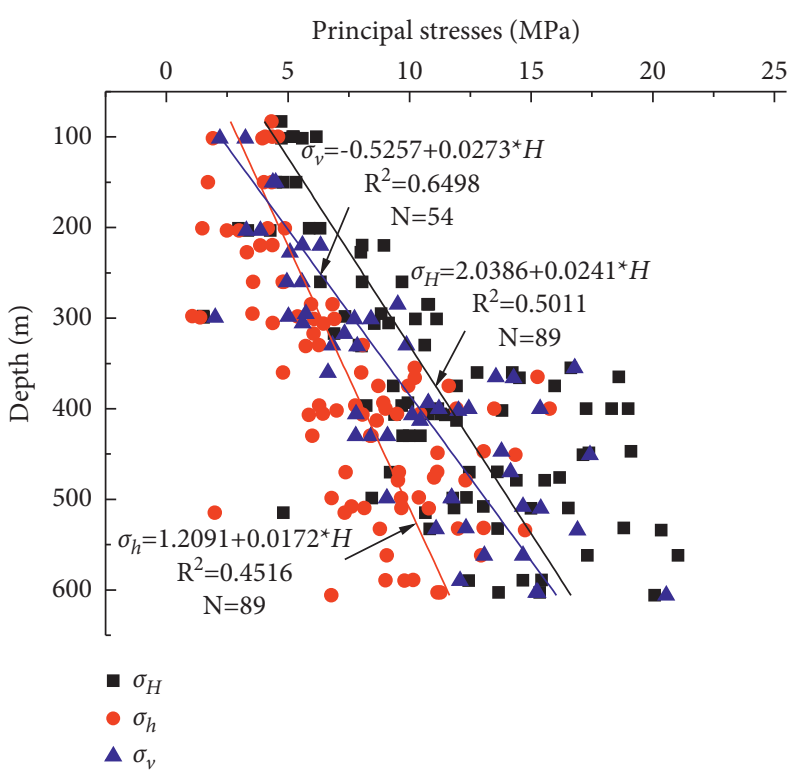

(a)

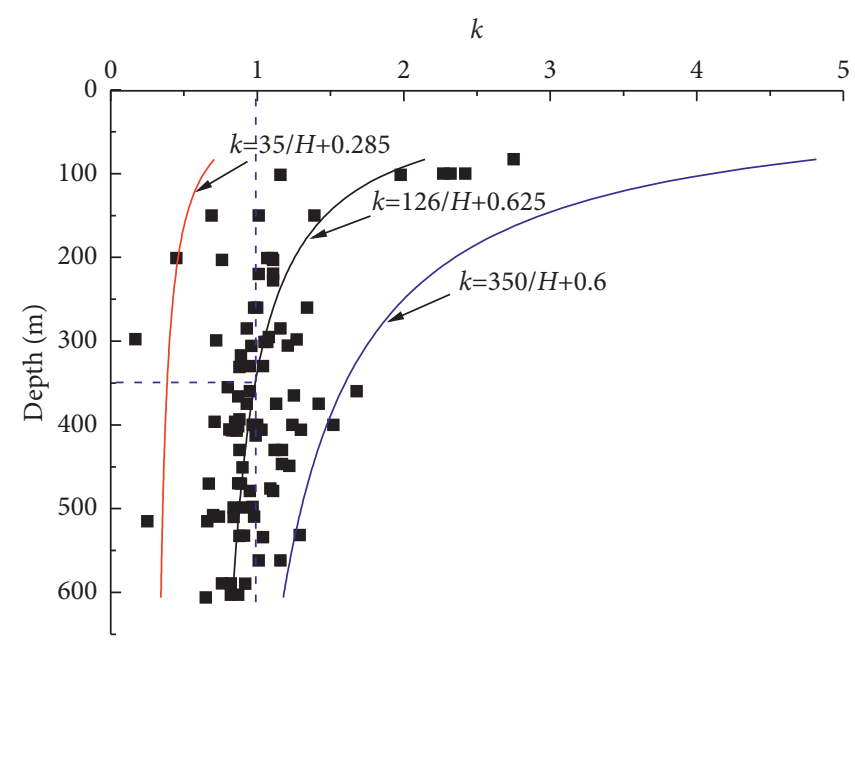

(b)

FIgure 1: In situ stress distribution in Burtai mine: (a) principal stress vs. depth and (b) $k$ vs. depth [24].

$$
\left.\begin{array}{l}
m_{b}=m_{i} \exp \left(\frac{\mathrm{GSI}-100}{28-14 D}\right) \\
s=\exp \left(\frac{\mathrm{GSI}-100}{9-3 \mathrm{D}}\right) \\
\alpha=\frac{1}{2}+\frac{1}{6}\left[\exp \left(-\frac{\mathrm{GSI}}{15}\right)-\exp \left(-\frac{20}{3}\right)\right]
\end{array}\right\},
$$

where $\sigma_{1}$ and $\sigma_{3}$ are the maximum and minimum principal stresses at failure, respectively; $\sigma_{c i}$ is the unconfined compressive strength; $m_{b}$ is a rock property, modified by the GSI and degree of disturbance of the rock mass, respectively; $s$ is a constant determined by the GSI and degree of disturbance of the rock mass; $\alpha$ is a constant determined by the GSI; $m_{\mathrm{i}}$, $s=1$, and $\alpha=0.5$ are the material constants for intact rock; and $D$ is a factor that depends upon the degree of disturbance to which the rock mass has been subjected to blast damage and stress relaxation.

When $\sigma_{\mathrm{tm}}<\sigma_{3}<\sigma_{\mathrm{ci}} / 4$, the expression is given by the following equation:

$$
\sigma_{c m}=\sigma_{c i} \frac{\left[m_{b}+4 s-\alpha\left(m_{b}-8 s\right)\right]\left(\left(m_{b} / 4\right)+s\right)^{\alpha-1}}{2(1+\alpha)(2+\alpha)} .
$$

Incorporating equation (6) into the Hoek-Brown strength criterion, let $\eta=\left[\sqrt{\left(1+\mu^{2}\right)}+\mu\right]^{2}, \sigma_{c i}=k_{m} \sigma_{c m}$. Then,

$$
\left.\begin{array}{l}
k_{m}=\frac{\sigma_{c i}}{\sigma_{c m}}=\frac{2(1+\alpha)(2+\alpha)}{\left[m_{b}+4 s-\alpha\left(m_{b}-8 s\right)\right]\left(\left(m_{b} / 4\right)+s\right)^{\alpha-1}} \\
\frac{\sigma_{c m}}{\sigma_{1}} \geq \frac{-m_{b}+\sqrt{\left(m_{b}\right)^{2}+4 s(\eta-1)^{2}}}{2 \eta s k_{m}}
\end{array}\right\} .
$$

The relationship between the $\sigma_{c m} / \sigma_{1}$ ratio and GSI for different friction coefficients is shown in Figure 2. With an increase in the friction coefficient, the $\sigma_{c m} / \sigma_{1}$ ratio changes significantly. When $0.2<\mu<0.6, \sigma_{c m} / \sigma_{1}$ ratio is between 0.01 and 0.3 , when $0.6<\mu<1.0, \sigma_{c m} / \sigma_{1}$ ratio lies between 0.05 and 0.7 , and the $\sigma_{c m} / \sigma_{1}$ ratio generally varies between 0.05 and 0.5 .

The relationship between the $\sigma_{c m} / \sigma_{1}$ ratio and GSI for different disturbance coefficients is shown in Figure 3. With a decrease in GSI, the variation of the disturbance coefficient $(D)$ increases, indicating that the deteriorating geological conditions increase the degree of disturbance in the in situ rock masses because of blasting, rock mass excavation, and rock mass unloading.

The in situ deformation tests of 50 groups of rock masses indicate that $D$ around the prospecting drift is 0.25 [32], while $D$ caused by the excavation of the mining roadway is less than 0.4 . When $\mu=0.3$ and $m_{i}=24$, the ratio of roadway excavation to $\sigma_{c m} / \sigma_{1}$ does not exceed 0.02 ; when $\mu=0.6$ and $m_{i}=24$, the ratio of roadway excavation to $\sigma_{c m} / \sigma_{1}$ exceeds 0.1 . Therefore, the mining roadway is less sensitive to $D$ compared to GSI.

The coal-measure strata are clastic sedimentary rocks, mainly sandstone. The values of $m_{i}$ for various rocks are as follows: siltstone $7 \pm 2$, hard sandstone $18 \pm 3$, sandstone $17 \pm 4$, conglomerate $21 \pm 3$, and breccia $19 \pm 5$ [30, 31]. Most mined sandstones have a core length greater than $10 \mathrm{~cm}$, and the joints are weakly weathered or non-weathered. The GSI of the surrounding rock of the coal seam is above $30-40$. The friction coefficient of sandstones ranges between 0.1 and 0.6 , with an average of 0.3 . The $\sigma_{c m} / \sigma_{1}$ ratio of sandstone in most coal-measure strata lies between 0.1 and 0.4 for different friction coefficients. The higher boundary value of the $\sigma_{c m} / \sigma_{1}$ ratio is suitable for most rock mass stress state evaluation of 

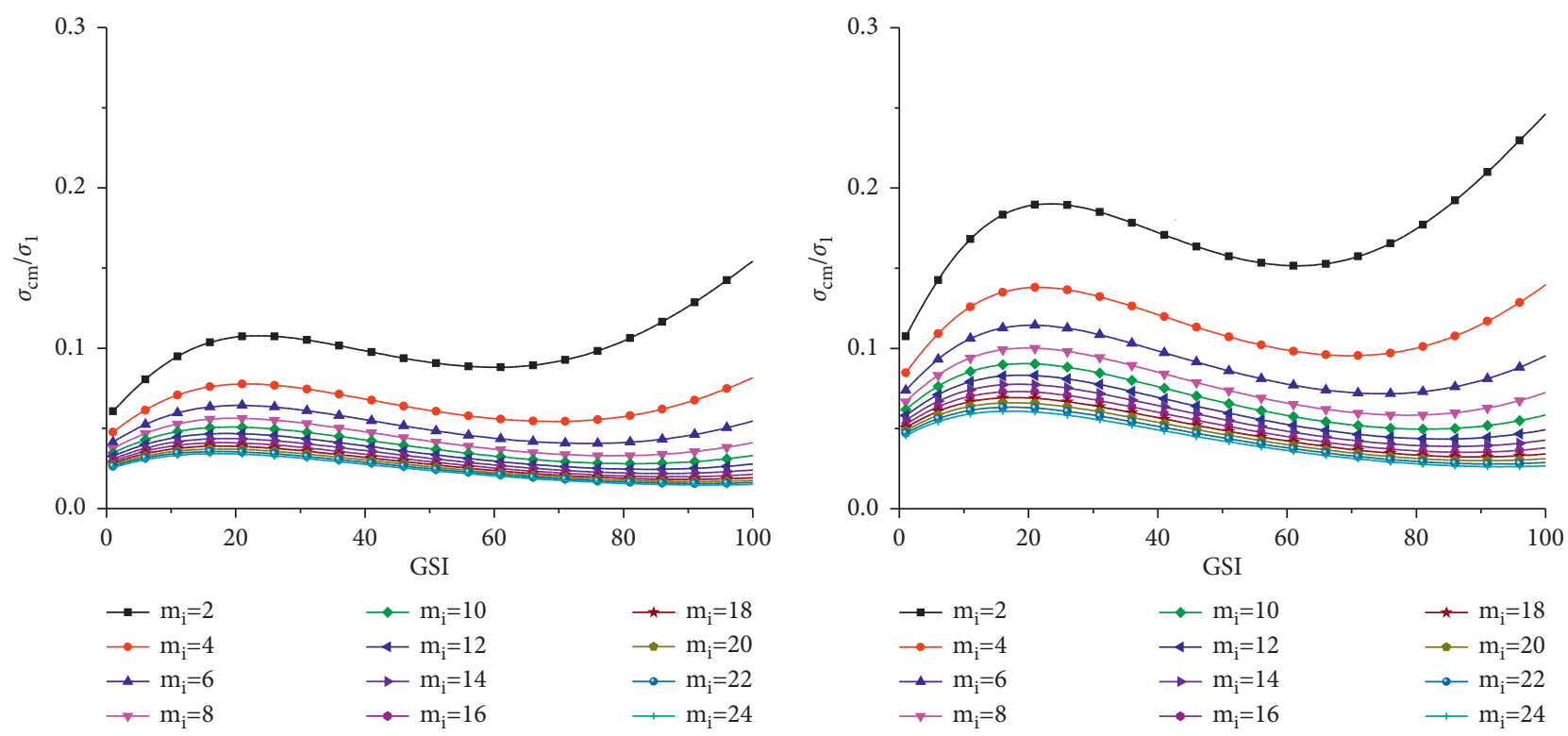

(a)
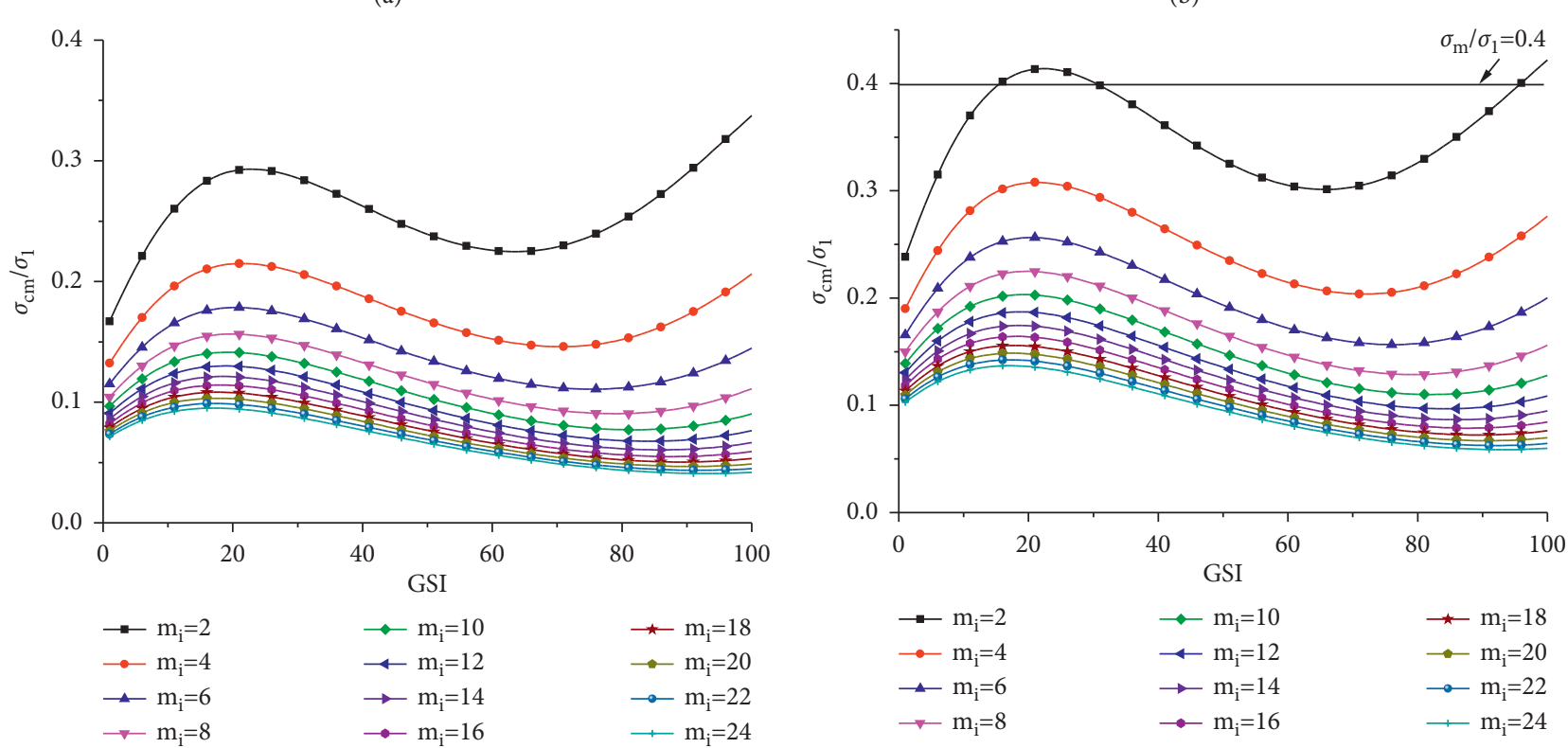

$$
\begin{array}{lll}
\rightarrow \mathrm{m}_{\mathrm{i}}=2 & \rightarrow-\mathrm{m}_{\mathrm{i}}=10 & \rightarrow \mathrm{m}_{\mathrm{i}}=18 \\
\rightarrow-\mathrm{m}_{\mathrm{i}}=4 & \hookrightarrow-\mathrm{m}_{\mathrm{i}}=12 & \rightarrow-\mathrm{m}_{\mathrm{i}}=20 \\
\rightarrow-\mathrm{m}_{\mathrm{i}}=6 & \rightarrow-\mathrm{m}_{\mathrm{i}}=14 & \rightarrow-\mathrm{m}_{\mathrm{i}}=22 \\
\rightarrow-\mathrm{m}_{\mathrm{i}}=8 & \rightarrow-\mathrm{m}_{\mathrm{i}}=16 & \rightarrow-\mathrm{m}_{\mathrm{i}}=24
\end{array}
$$

$$
\begin{aligned}
& -\mathrm{m}_{\mathrm{i}}=2 \\
& \rightarrow-\mathrm{m}_{\mathrm{i}}=4 \\
& \leftarrow \mathrm{m}_{\mathrm{i}}=6 \\
& \rightarrow \mathrm{m}_{\mathrm{i}}=8
\end{aligned}
$$$$
\rightarrow \mathrm{m}_{\mathrm{i}}=10
$$$$
\multimap \mathrm{m}_{\mathrm{i}}=12
$$$$
\rightarrow \mathrm{m}_{\mathrm{i}}=14
$$$$
\rightarrow \mathrm{m}_{\mathrm{i}}=16
$$$$
\text { * } \mathrm{m}_{\mathrm{i}}=18
$$$$
\rightarrow \mathrm{m}_{\mathrm{i}}=20
$$$$
\therefore \mathrm{m}_{\mathrm{i}}=22
$$

(b)

(c)

(d)

Figure 2: Continued. 

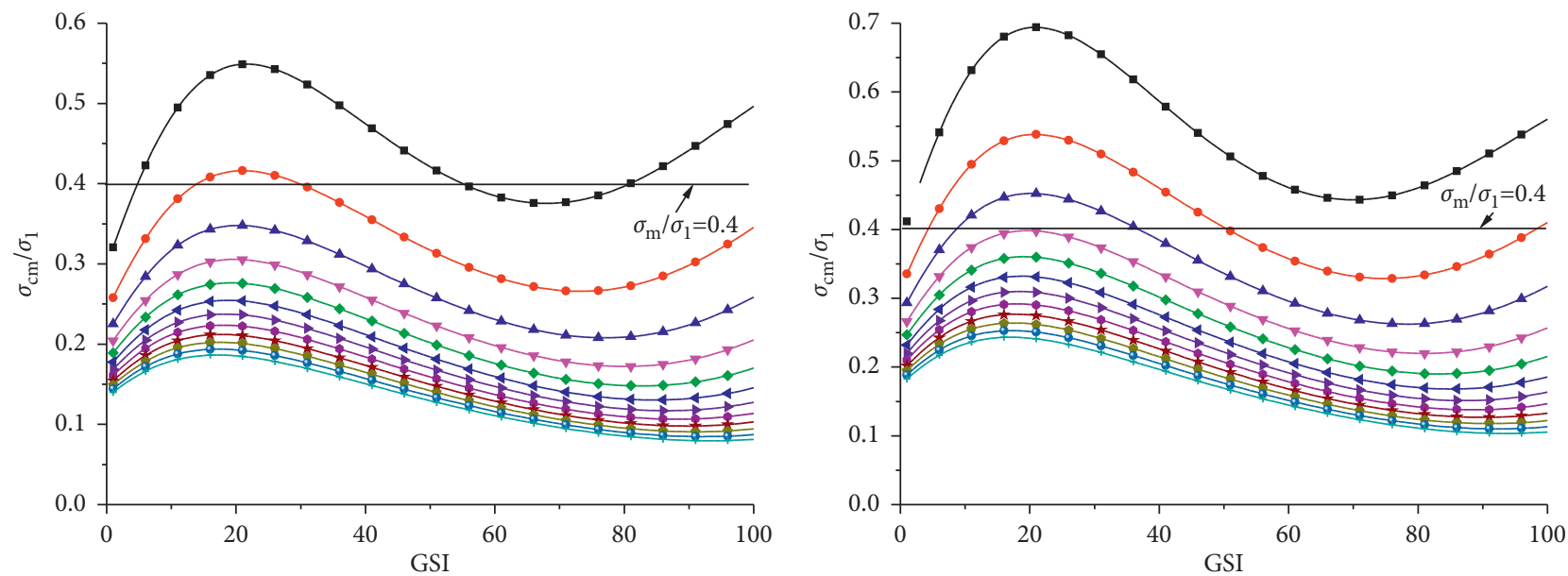

$$
\begin{array}{lll}
\rightarrow \mathrm{m}_{\mathrm{i}}=2 & \rightarrow \mathrm{m}_{\mathrm{i}}=10 & \rightarrow \mathrm{m}_{\mathrm{i}}=18 \\
\rightarrow \mathrm{m}_{\mathrm{i}}=4 & \multimap \mathrm{m}_{\mathrm{i}}=12 & \rightarrow-\mathrm{m}_{\mathrm{i}}=20 \\
\rightarrow \mathrm{m}_{\mathrm{i}}=6 & \rightarrow-\mathrm{m}_{\mathrm{i}}=14 & \rightarrow-\mathrm{m}_{\mathrm{i}}=22 \\
\rightarrow \mathrm{m}_{\mathrm{i}}=8 & \rightarrow \mathrm{m}_{\mathrm{i}}=16 & \rightarrow-\mathrm{m}_{\mathrm{i}}=24
\end{array}
$$

(e)

$$
\begin{aligned}
& \multimap \mathrm{m}_{\mathrm{i}}=2 \\
& \rightarrow \mathrm{m}_{\mathrm{i}}=4 \\
& \neg \mathrm{m}_{\mathrm{i}}=6 \\
& \rightarrow \mathrm{m}_{\mathrm{i}}=8
\end{aligned}
$$$$
\rightarrow-\mathrm{m}_{\mathrm{i}}=10
$$$$
\text { \# } \mathrm{m}_{\mathrm{i}}=18
$$$$
\rightarrow-\mathrm{m}_{\mathrm{i}}=14
$$$$
\rightarrow-\mathrm{m}_{\mathrm{i}}=20
$$$$
\multimap-\mathrm{m}_{\mathrm{i}}=16
$$$$
\because \mathrm{m}_{\mathrm{i}}=22
$$

(f)

FIGURE 2: Relationship between $\sigma_{c m} / \sigma_{1}$ and GSI under different friction coefficients. (a) $\mu=0.3$. (b) $\mu=0.4$. (c) $\mu=0.5$. (d) $\mu=0.6$. (e) $\mu=0.7$. (f) $\mu=0.8$.
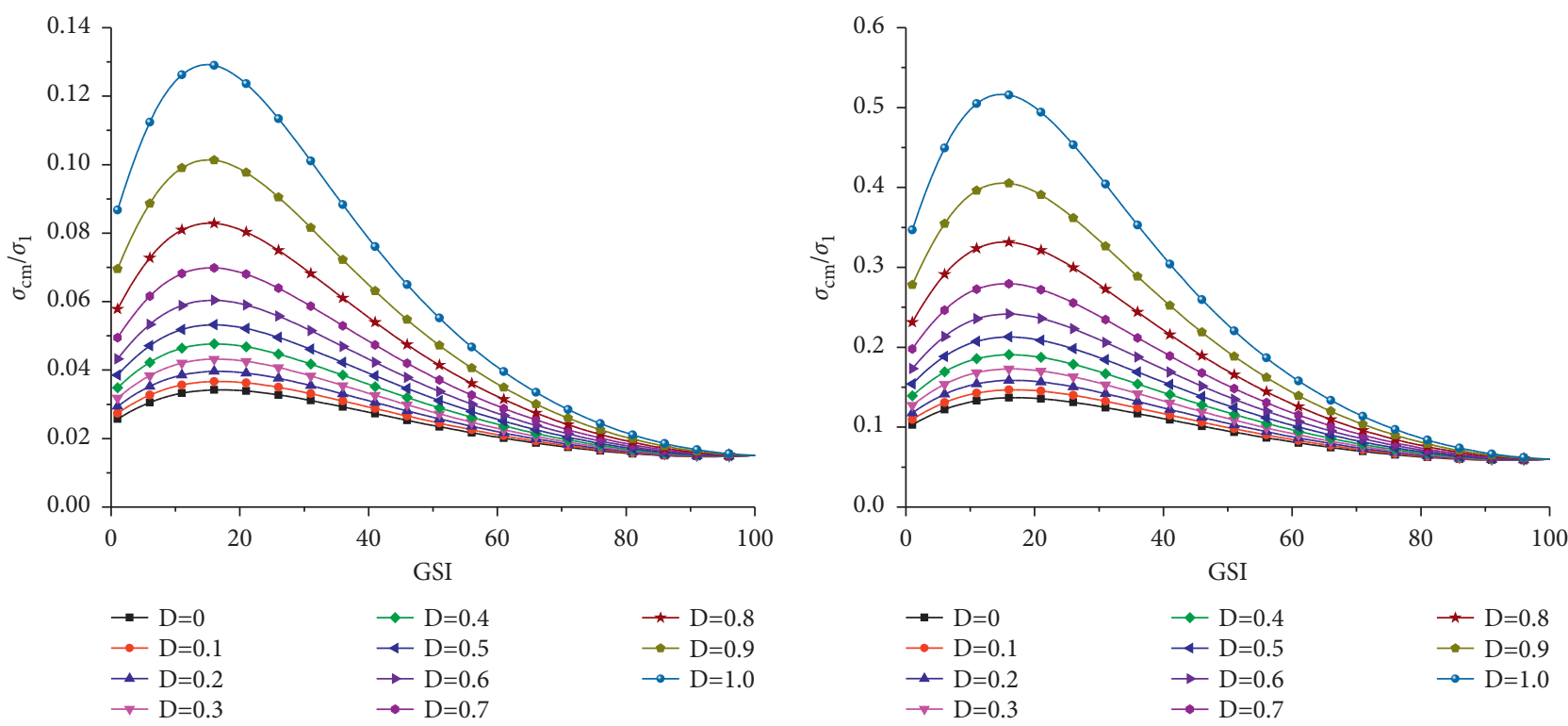

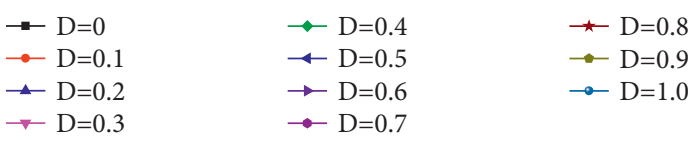

(a)

(b)

FIGURE 3: Relationship between $\sigma_{c m} / \sigma_{1}$ and GSI under different disturbance coefficients. (a) $\mu=0.3, m_{i}=24$. (b) $\mu=0.6, m_{i}=24$. 
coal-measure strata. The rock mass stress will significantly impact its stability for $\sigma_{c m} / \sigma_{1}<0.4$ and may cause rock mass instability, which is defined as a state of rock mass with high stress.

Stress concentrations occur in the rock mass around the roadway during underground mining. Therefore, the stress concentration factor should be considered for calculating the maximum principal stress in the rock mass; hence, $\sigma_{1}$ can be expressed as

$$
\sigma_{1}=\eta \sigma_{1 m}
$$

where $\eta$ is the maximum stress concentration factor of the rock mass around the roadway and $\sigma_{1 m}$ is the measured maximum principal stress.

The rock surrounding the roadway is a nonhomogeneous, discontinuous, and nonlinear material with complicated loading and boundary conditions. For a circular roadway, the maximum stress concentration factor is 2.0 and 3.0 under uniform and nonuniform stress field conditions, respectively. The maximum stress concentration factor for a rectangular roadway stays below 4.0 and is generally less than 3.5. Under most coal seam and mining conditions, the front abutment pressure of the working face is in the range of 2.5-3.5 [33]. At $\eta=3.5$, the rock mass starts to fail for $\sigma_{c m} / \sigma_{1 m}<1.4$, which corresponds to a high in situ stress state. The corners where the two working faces meet experience stress concentration seven times the vertical stress of the original rock, or even higher. The rock mass failure occurs locally in the roadway section for $\eta=9.0$ and $1.4<\sigma_{c m} / \sigma_{1 m}<3.6$, and the stress state corresponds to the middle in situ stress state. When $\sigma_{c m} /$ $\sigma_{1 m}>3.6$, local rock mass collapses, or the structural plane becomes unstable because it is difficult to achieve a ninefold stress concentration factor in coal-measure strata, and this corresponds to a low in situ stress state. Based on the strengthstress ratio, the evaluation index for the rock mass stress state of coal mines is presented in Table 1.

$\sigma_{c m}$ is the unconfined compressive strength of the original rock mass of the surrounding rock of the roadway and can be estimated using the Hoek-Brown strength criterion (equation (4)) or using RocData software; $\sigma_{1 m}$ is the maximum principal stress in the in situ stress field of the surrounding rock of the roadway, which can be calculated using the theoretical model of in situ stress, or obtained using in situ stress testing.

3.2. Engineering Verification. The relationship between $\sigma_{\mathrm{cm}} /$ $\sigma_{1 m}$ and the depth of all rock formations in the Burtai mine is used to verify the in situ stress evaluation index of the rock mass strength-stress ratio (Table 1) as shown in Figure 4(a). The roof and floor data around the 22\#, 42\#, and 52\# down coal seams are shown in Figure 4(b), where $\sigma_{c i}$ is the average uniaxial compressive strength of the rock, $\sigma_{c m}$ is the average rock mass strength, and $\sigma_{1 m}$ is the measured maximum principal stress. GSI is determined using a combination of the rock quality designation (RQD), the rock block index (RBI), and the core recovery percentage (CRP), with the disturbance coefficient $D$ set to 0 . The parameters are listed in Tables 2 and 3.
Figure 4(a) shows 89 measuring points in the Burtai mine, of which 59 , with $\sigma_{c m} / \sigma_{1 m}<1.4$, account for $66.3 \%$ of the total; 27, with $1.4<\sigma_{c m} / \sigma_{1 m}<3.6$, account for $30.3 \%$; and 3, with $\sigma_{c m} / \sigma_{1 m}>3.6$, account for $3.4 \%$. In Figure 4(b), among the 24 measuring points in Burtai mine, 11, with $\sigma_{\mathrm{cm}} /$ $\sigma_{1 m}<1.4$, account for $45.8 \%$ of the total; 12 , with $1.4<\sigma_{c m} /$ $\sigma_{1 m}<3.6$, account for $50.0 \%$; and 1 , with $\sigma_{c m} / \sigma_{1 m}>3.6$, accounts for $4.2 \%$. The average values of $\sigma_{c m} / \sigma_{1 m}$ of the roof and floor around 22\#, 42\#, and 52\# down coal seams were $1.59,1.25$, and 2.00 , respectively. The groups with $\sigma_{c m} /$ $\sigma_{1 m}<1.4$ are divided according to the depth into $350-450 \mathrm{~m}$, $450-550 \mathrm{~m}$, and $550-650 \mathrm{~m}$, which account for $37.5 \%$, $50.0 \%$, and $42.9 \%$ of the total, respectively. The ratio of $\sigma_{\mathrm{cm}} /$ $\sigma_{1 m}<1.4$ increases with an increase in the depth, indicating the Burtai mine to be a medium-high in situ stress field.

According to the empirical method, 39 groups with $\sigma_{h}<10 \mathrm{MPa}$ account for $43.8 \%$ of the total; 42 with $10<\sigma_{H}<18 \mathrm{MPa}$ account for $47.2 \%$; and 8 with $\sigma_{H}>18 \mathrm{MPa}$ account for $9 \%$. Among them, 34 groups were above $350 \mathrm{~m}$, of which 29 groups with $\sigma_{h}<10 \mathrm{MPa}$, account for $85.3 \%$; 55 groups were below $350 \mathrm{~m}$, of which 11 groups with $\sigma_{h}<10 \mathrm{MPa}$ account for $20 \%$; and $65.5 \%$ groups have $10<\sigma_{h}<18 \mathrm{MPa}$. Therefore, the in situ stress field in the Burtai mine is low in situ stress field above $350 \mathrm{~m}$ and medium in situ stress field below $350 \mathrm{~m}$. According to the stress ratio method, there are 86 groups with $\left(\sigma_{1}+\sigma_{2}+\sigma_{3}\right) /$ $\sigma_{V}>2$, accounting for $96.6 \%$ of the total, indicating the majority of the Burtai mine as high in situ stress field, which does not conform to the actual condition of the Burtai mine.

The current mining depth of $42 \#$ coal seam in the Burtai mine is greater than $400 \mathrm{~m}$, resulting in nonlinear dynamic phenomena such as bottom heave, slab, and large-area roof weighting. With a further increase in mining depth, the roof and floor will be under high in situ stress along with an increase in the accumulated elastic energy. This justifies the medium-high in situ stress field of the Burtai mine and necessitates the active adoption of the mine pressure prevention technology, and establishes the reliability and applicability of the strength-stress ratio index.

\section{Numerical Simulation of the Stress Field in Repeated Mining of Coal Seams}

4.1. Model Construction. We analyzed six log sheets (E014, E019, E026, E030, E051, and E060) around the 42107 working face in the Burtai mine corresponding to the SJ-3 log sheet on the 42105 working face [34]. The representative marker layer, which roughly divides the Burtai mine into 15 strata from top to bottom, was selected as the strata interface. A refined three-dimensional geological model of the working face was constructed using Rhinoceros software and imported into Flac3D using griddle software (Figure 5). The spatial position of the working face is illustrated in Figure 6 . The numerical model of the working face was length $\times$ width $\times$ height $=800 \mathrm{~m} \times 900 \mathrm{~m} \times 600 \mathrm{~m}$, and it was divided into $1,605,551$ units and 283,006 nodes. The initial conditions of the model are determined in combination with the measured in situ stress regression model (equation (1)). 
TABLe 1: Evaluation index of the rock mass stress state by the strength-stress ratio.

\begin{tabular}{lcccc}
\hline Evaluation index & \multicolumn{2}{c}{ Index value } & Middle & Low \\
\hline$\sigma_{c m} / \sigma_{1 m}$ & High & $<1.4$ & $1.4 \sim 3.6$ & $>3.6$ \\
\hline
\end{tabular}

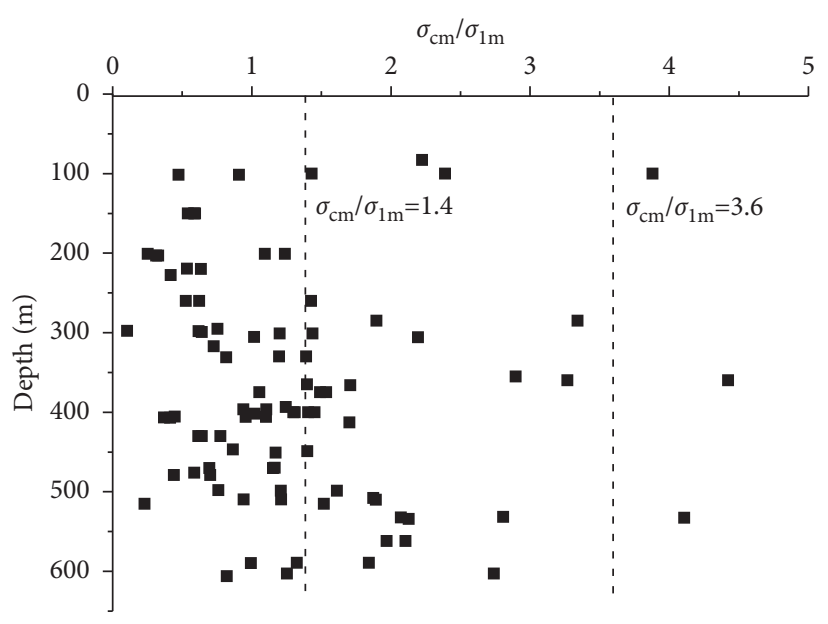

(a)

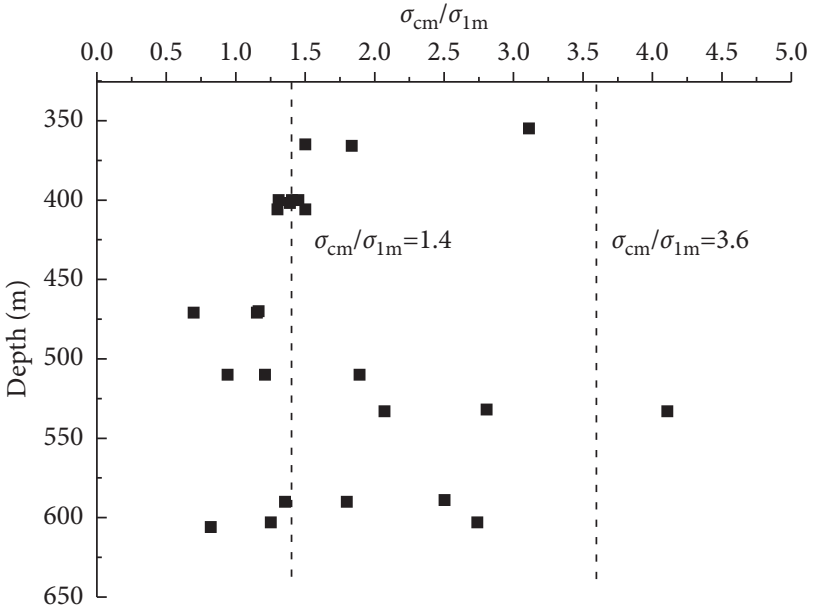

(b)

FIgURE 4: $\sigma_{c m} / \sigma_{1 m}$ vs. depth: (a) all rock formations and (b) roof and floor.

TABLE 2: Rock mass strength estimation and measured maximum principal stress.

\begin{tabular}{|c|c|c|c|c|c|c|c|c|c|c|}
\hline Drilling number & Lithology & Depth $(\mathrm{m})$ & $\sigma_{c i}(\mathrm{MPa})$ & $\sigma_{1 m}(\mathrm{MPa})$ & CRP (\%) & GSI & $m_{i}$ & $\sigma_{c m}(\mathrm{MPa})$ & $\sigma_{c m} / \sigma_{1 m}$ & $E_{m}(\mathrm{GPa})$ \\
\hline \multirow{6}{*}{ BK212 } & Coarse sandstone & 102 & 9.28 & 5.17 & 49 & 55 & 15 & 2.18 & 0.42 & 4.06 \\
\hline & Medium sandstone & 203 & 6.14 & 3.81 & 28 & 50 & 15 & 1.30 & 0.34 & 2.48 \\
\hline & Sandy mudstone & 304 & 7.96 & 3.32 & 82 & 70 & 15 & 2.63 & 0.79 & 8.92 \\
\hline & Fine sandstone & 406 & 21.41 & 9.64 & 27 & 50 & 15 & 4.53 & 0.47 & 4.63 \\
\hline & Fine sandstone & 510 & 43.44 & 14.46 & 99 & 80 & 21 & 21.24 & 1.47 & 37.06 \\
\hline & Fine sandstone & 590 & 40.45 & 13.66 & 93 & 90 & 21 & 26.90 & 1.97 & 63.60 \\
\hline \multirow{4}{*}{ BK209 } & Sandy mudstone & 222 & 12.52 & 4.90 & 89 & 75 & 13 & 4.46 & 0.91 & 14.92 \\
\hline & Fine sandstone & 330 & 23.53 & 8.77 & 88 & 75 & 21 & 10.10 & 1.15 & 20.46 \\
\hline & Fine sandstone & 403 & 26.27 & 12.10 & 90 & 90 & 21 & 17.47 & 1.44 & 51.25 \\
\hline & Siltstone & 497 & 36.39 & 13.48 & 62 & 65 & 18 & 11.57 & 0.86 & 14.31 \\
\hline \multirow{4}{*}{ BK213 } & Fine sandstone & 300 & 22.91 & 5.74 & 59 & 60 & 21 & 7.02 & 1.22 & 8.51 \\
\hline & Siltstone & 400 & 34.22 & 10.86 & 89 & 75 & 18 & 13.80 & 1.27 & 24.67 \\
\hline & Siltstone & 469 & 33.04 & 11.91 & 89 & 75 & 18 & 13.33 & 1.12 & 24.24 \\
\hline & Fine sandstone & 532 & 128.94 & 15.62 & 73 & 60 & 21 & 39.52 & 2.53 & 17.78 \\
\hline \multirow{7}{*}{ BK207 } & Coarse sandstone & 100 & 48.62 & 5.54 & 64 & 60 & 18 & 13.86 & 2.50 & 12.40 \\
\hline & Coarse sandstone & 201 & 12.91 & 5.84 & 88 & 75 & 18 & 5.21 & 0.89 & 15.15 \\
\hline & Coarse sandstone & 260 & 18.86 & 16.64 & 44 & 65 & 21 & 6.00 & 0.36 & 10.30 \\
\hline & Siltstone & 301 & 33.18 & 9.97 & 92 & 80 & 18 & 15.33 & 1.54 & 32.39 \\
\hline & Medium sandstone & 362 & 116.25 & 17.97 & 55 & 60 & 18 & 33.14 & 1.84 & 17.78 \\
\hline & Siltstone & 400 & 51.64 & 18.19 & 98 & 80 & 21 & 25.25 & 1.39 & 40.41 \\
\hline & Siltstone & 449 & 65.46 & 17.97 & 54 & 60 & 21 & 20.06 & 1.12 & 14.39 \\
\hline \multirow{7}{*}{ BK220 } & Coarse sandstone & 83 & 46.62 & 4.72 & 44 & 50 & 17 & 10.49 & 2.22 & 9.11 \\
\hline & Coarse sandstone & 150 & 5.67 & 4.89 & 92 & 80 & 21 & 2.77 & 0.57 & 13.39 \\
\hline & Coarse sandstone & 285 & 77.92 & 10.78 & 96 & 70 & 17 & 27.11 & 2.51 & 27.91 \\
\hline & Medium sandstone & 375 & 90.85 & 12.97 & 99 & 70 & 17 & 31.61 & 2.44 & 30.14 \\
\hline & Coarse sandstone & 430 & 22.44 & 10.05 & 75 & 60 & 21 & 6.88 & 0.68 & 8.42 \\
\hline & Sandy mudstone & 562 & 51.40 & 19.57 & 95 & 95 & 21 & 23.27 & 1.19 & 40.32 \\
\hline & Medium sandstone & 603 & 84.64 & 17.04 & 65 & 60 & 21 & 25.94 & 1.52 & 16.36 \\
\hline
\end{tabular}


TABLE 3: Strength estimation and measured maximum principal stress in the roof and floor.

\begin{tabular}{|c|c|c|c|c|c|c|c|c|c|c|}
\hline Rock formation & Lithology & Depth $(\mathrm{m})$ & $\sigma_{c i}(\mathrm{MPa})$ & $\sigma_{1 m}(\mathrm{MPa})$ & CRP (\%) & GSI & $m_{i}$ & $\sigma_{c m}(\mathrm{MPa})$ & $\sigma_{c m} / \sigma_{1 m}$ & $E_{m}(\mathrm{GPa})$ \\
\hline \multirow{3}{*}{$22 \#$ coal roof } & Fine sandstone & 402 & 28.87 & 13.81 & 90 & 90 & 21 & 14.11 & 1.02 & 25.68 \\
\hline & Fine sandstone & 406 & 22.08 & 11.28 & 90 & 90 & 21 & 10.79 & 0.96 & 22.46 \\
\hline & Fine sandstone & 406 & 24.31 & 10.77 & 90 & 90 & 21 & 11.89 & 1.10 & 23.57 \\
\hline \multirow{3}{*}{$22 \#$ coal floor } & Medium sandstone & 366 & 87.00 & 14.52 & 55 & 60 & 18 & 26.66 & 1.84 & 16.59 \\
\hline & Medium sandstone & 355 & 170.55 & 16.79 & 55 & 60 & 18 & 52.27 & 3.11 & 17.78 \\
\hline & Medium sandstone & 365 & 91.19 & 18.61 & 55 & 60 & 18 & 27.95 & 1.50 & 16.98 \\
\hline \multirow{6}{*}{$42 \#$ coal roof } & Siltstone & 400 & 51.27 & 17.27 & 98 & 80 & 21 & 25.07 & 1.45 & 40.27 \\
\hline & Siltstone & 400 & 49.04 & 18.31 & 98 & 80 & 21 & 23.98 & 1.31 & 39.38 \\
\hline & Siltstone & 400 & 54.61 & 18.99 & 98 & 80 & 21 & 26.70 & 1.41 & 41.56 \\
\hline & Fine sandstone & 510 & 31.87 & 16.54 & 99 & 80 & 21 & 15.58 & 0.94 & 31.75 \\
\hline & Fine sandstone & 510 & 33.50 & 13.51 & 99 & 80 & 21 & 16.38 & 1.21 & 32.55 \\
\hline & Fine sandstone & 510 & 59.58 & 15.40 & 99 & 80 & 21 & 29.13 & 1.89 & 43.41 \\
\hline \multirow{3}{*}{ 42\# coal floor } & Siltstone & 470 & 40.90 & 14.15 & 89 & 75 & 18 & 16.50 & 1.17 & 26.97 \\
\hline & Siltstone & 471 & 35.59 & 12.46 & 89 & 75 & 18 & 14.35 & 1.15 & 25.16 \\
\hline & Siltstone & 471 & 21.52 & 12.46 & 89 & 75 & 18 & 8.68 & 0.70 & 19.56 \\
\hline \multirow{6}{*}{ 52\# down coal roof } & Fine sandstone & 532 & 172.27 & 18.81 & 73 & 60 & 21 & 52.80 & 2.81 & 17.78 \\
\hline & Fine sandstone & 533 & 95.43 & 14.11 & 73 & 60 & 21 & 29.25 & 2.07 & 17.37 \\
\hline & Fine sandstone & 533 & 148.65 & 11.09 & 73 & 60 & 21 & 45.56 & 4.11 & 17.78 \\
\hline & Fine sandstone & 590 & 25.33 & 12.43 & 93 & 90 & 21 & 12.37 & 1.00 & 24.04 \\
\hline & Fine sandstone & 590 & 42.27 & 15.62 & 93 & 90 & 21 & 20.68 & 1.32 & 31.09 \\
\hline & Fine sandstone & 589 & 58.80 & 15.61 & 93 & 90 & 21 & 28.75 & 1.84 & 36.65 \\
\hline \multirow{3}{*}{ 52\# down coal floor } & Medium sandstone & 603 & 62.72 & 15.35 & 65 & 60 & 21 & 19.22 & 1.25 & 14.08 \\
\hline & Medium sandstone & 603 & 136.11 & 15.22 & 65 & 60 & 21 & 41.71 & 2.74 & 17.78 \\
\hline & Medium sandstone & 606 & 55.08 & 20.55 & 65 & 60 & 21 & 16.88 & 0.82 & 13.20 \\
\hline
\end{tabular}

siltstone 1

pebbly_coarse_sands

fine_sandst

sandy_mudsto 1

sandy_mudsto2

loess

coarse_sands

fine_sandst 2

medium_sandst

siltstone 2

sandy_mudst 4

sandy_mudst 3

$22 \mathrm{coal}$

fine sandst 3

$42 \mathrm{coal}$

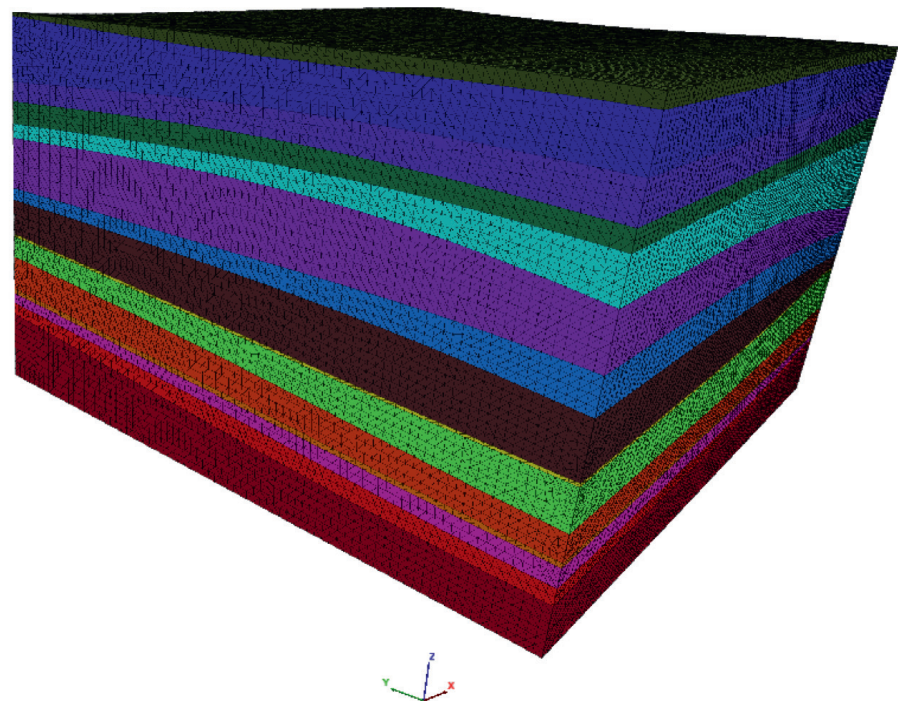

FIgURE 5: Refined numerical geological model of the working face.

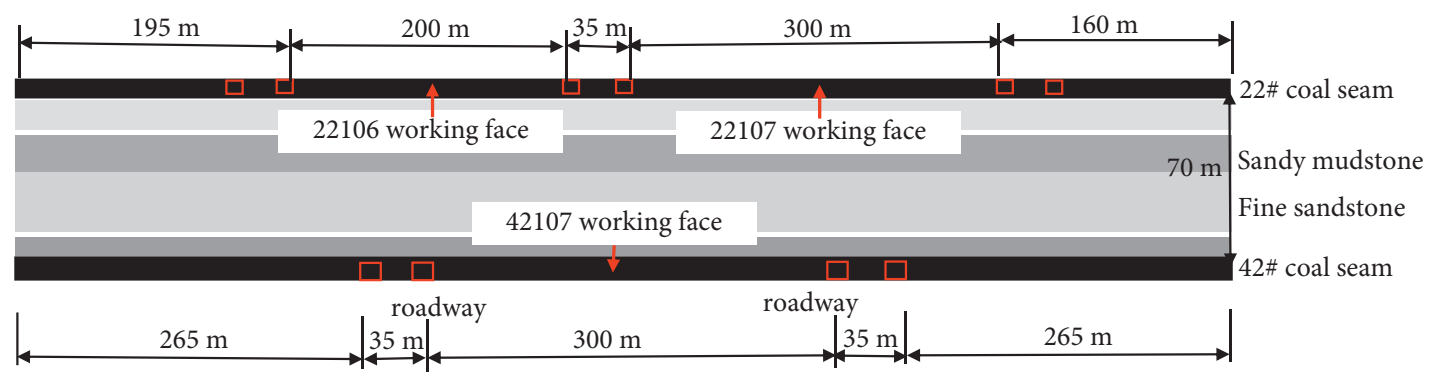

FIGURE 6: Layout diagram of the spatial arrangement of the working face. 
The physical and mechanical parameters of the model strata were determined using laboratory tests of the coal and rock in the SJ-3 borehole at 42105 working face in the Burtai mine [34]. The tensile strength of rock mass $\left(\sigma_{t m}\right)$ is calculated by RocLab 1.0 software (Table 4 ).

The rock follows the Mohr-Coulomb elastoplastic model, while the broken rock mass in the caving zone follows the double-yield-surface elastoplastic model. Based on the compaction characteristics of the broken rock mass, the stress-strain relationship of the caving zone rock mass aligns well with the actual conditions of the coal mine and is given by the following equation:

$$
\sigma_{v}=\frac{E_{0} \varepsilon}{1-\left(\varepsilon / \varepsilon_{m}\right)},
$$

where $\sigma_{v}$ is the vertical stress of the caving zone in the gob $(\mathrm{MPa}) ; \varepsilon$ is the vertical strain, $\varepsilon_{m}$ is the maximum vertical strain, taken as $\varepsilon_{m}=(b-1) / b ; b$ is the comprehensive crushing expansion coefficient of the rock mass in the caving zone, calculated using the caving zone $H_{c}=h /(b-1) ; E_{0}$ is the initial elasticity modulus of the rock mass, $\mathrm{MPa}$, calculated using $E_{0}=10.39 \sigma_{c}{ }^{1.042} / b^{7.7}[35]$; and $\sigma_{c}$ is the uniaxial compressive strength (UCS) of the rock mass in the caving zone, MPa.

The UCS of the roof above $22 \#$ and $42 \#$ coal seams are greater than $40 \mathrm{MPa}$, indicating them to be hard rock strata. According to the coal mining conditions, the average thickness of coal seam $22 \#$ is $3.6 \mathrm{~m}$, and the average thickness of the $42 \#$ coal seam, which uses mechanized mining with sublevel caving technology, is $6.5 \mathrm{~m}$. The machine mining height is $3.6 \mathrm{~m}$, the coal caving height is $2.9 \mathrm{~m}$, and the top coal caving rate is $80 \%$, indicating the actual mining height of the $42 \#$ coal seam to be $5.92 \mathrm{~m}$. The heights of the caving zone $\left(H_{c}\right)$ and the fissure zone $\left(H_{f}\right)$ can be calculated using equations (10) and (11) and Table 5 [35-37]. The heights of the two zones formed after the $22 \#$ and $42 \#$ coal seam working faces with longwall mining are $15.3 \mathrm{~m}, 57.0 \mathrm{~m}$, and $20.8 \mathrm{~m}$; and $65.0 \mathrm{~m}, 1.236$ and 1.284 , respectively; and $\varepsilon_{m}$ is 0.19 and 0.22 , respectively. The mechanical parameters of the caving zone rock mass in the gob are tabulated in Table 6.

$$
\begin{aligned}
& H_{c}=\frac{100 h}{c_{1} h+c_{2}}, \\
& H_{f}=\frac{100 h}{c_{3} h+c_{4}} .
\end{aligned}
$$

4.2. Results and Analysis. The impact of the overlying pillar on the mining face was determined using simulations of simultaneous upper and lower coal seam mining. The widths of overlying 22\# coal seam pillars are $5 \mathrm{~m}, 15 \mathrm{~m}, 25 \mathrm{~m}, 35 \mathrm{~m}$, and $45 \mathrm{~m}$. Coal seam 42\# lags the $22 \#$ coal seam by $300 \mathrm{~m}$, and the excavation distance is $300 \mathrm{~m}$. Two survey lines ( $117 \mathrm{~m}$ and $200 \mathrm{~m}$ from the return roadway) on strike and one survey line ( $5 \mathrm{~m}$ from the rib) in an inclined direction are arranged on the main roof of the 42107 working face at the height of $25 \mathrm{~m}$ from the working face. The principal stress distribution of the main roof under different pillars and the gob is monitored, as shown in Figure 7.

4.2.1. Maximum Principal Stress Distribution on the Strike. $\sigma_{1}$ of the main roof ( $380 \mathrm{~m}$ deep) above $42 \#$ coal seam increases by $10 \mathrm{MPa}$ when advancing $350 \mathrm{~m}$ because of the overlying pillars of 22\# coal seam (Figures 7(a) and 7(c)). The principal stress increases by different degrees with the increase in the width of the pillar from $300 \mathrm{~m}$. The larger the pillar width, the faster the increase in stress. The increase rate increases from $60 \mathrm{~m}$ advances and reaches the maximum for 4-9 $\mathrm{m}$ advances. The rate decreases rapidly above and behind the working face and reduces to $6 \mathrm{MPa}$ and $30 \mathrm{~m}$ behind the gob. Original rock stress zones, stress increase zones, and stress reduction zones are present on the strike of the working face under the pillar, and the size of the stress increase zone is different under different pillars. Although $\sigma_{1}$ increases with an increase in pillar width, the rate of increase reduces, while the principal stress influence ranges remain unchanged. The peak value distance from the rib is approximately $3 \mathrm{~m}$, and the stress peak coefficients are 1.95, $2.19,2.31,2.35$, and 2.45 , respectively, under different pillar widths. The distribution of $\sigma_{1}$ on strike under the gob is similar to that under the pillar, and the peak coefficients are reduced to $1.32,1.41,1.47,1.56$, and 1.66 , respectively.

The roof $\sigma_{1}$ direction of the working face under the pillar is first deflected towards the $z$-axis in the advanced range and then deflected in the reverse direction (Figures $7(\mathrm{~b})$ and $7(\mathrm{~d}))$. The angle between the $\sigma_{1}$ direction and the $z$-axis is $6^{\circ}$ for advancing $350 \mathrm{~m}$, and it is biased towards the gob. The angle increases to $13^{\circ}$ from advancing $300 \mathrm{~m}$ and gradually decreases to $3^{\circ}$ for $50 \mathrm{~m}$. The angle remains constant with the increase in pillar width, and the reverse deflection occurs within advancing $50 \mathrm{~m}$, reaching $30^{\circ}$ above the working face, and $55^{\circ}$ at $30 \mathrm{~m}$ behind the gob. The deviation of the $\sigma_{1}$ direction below the pillar remains constant beyond $350 \mathrm{~m}$ and is subsequently affected by the overlying coal mining. The angle between the $\sigma_{1}$ direction and the $z$-axis increases sharply to $68^{\circ}$ within advancing $350 \mathrm{~m}$ to $250 \mathrm{~m}$. Subsequently, reverse deflection occurs, and the angle decreases. The deflection angle ranges between $50^{\circ}$ and $80^{\circ}$ and decreases with an increase in pillar width, with a sharp decrease to $35^{\circ}$ within advancing $16 \mathrm{~m}$. After the working face, the $\sigma_{1}$ direction continues to deflect to the gob, and the deflection reaches $60^{\circ}$ for $25 \mathrm{~m}$ behind the gob. The main roof $\sigma_{1}$ deflection angle within $25 \mathrm{~m}$ in front of the rib under the gob is $35^{\circ}$ because of the overlying coal mining and is $10^{\circ}$ larger than solid coal. The friction coefficient of rock is distributed between $0.1^{\circ}$ and $0.8^{\circ}$, and the predominant fracture angle is $25-45^{\circ}$, as seen from the Griffith physical model of closed microcrack propagation under pressure [38]. The shear-type (II) and tension-shear mixed-type (I-II) expansion of the coal and rock mass cracks are observed along the vertical plane within the severely affected range of mining. The principal stress of the roof remains unchanged, and the principal stress direction is rotated according to the conditions of the tensile type (I) expansion of the roof cracks [38]. When $\sigma_{1}$ rotates to the dominant angle, the maximum 
TABLE 4: Physical and mechanical parameters of the model strata.

\begin{tabular}{|c|c|c|c|c|c|c|c|c|}
\hline Lithology & $\rho\left(\mathrm{kg} \cdot \mathrm{m}^{-3}\right)$ & $E(\mathrm{GPa})$ & $v$ & $G(\mathrm{GPa})$ & $K(\mathrm{GPa})$ & $C(\mathrm{MPa})$ & $\varphi\left({ }^{\circ}\right)$ & $\sigma_{t m}(\mathrm{MPa})$ \\
\hline Loess & 1600 & 0.30 & 0.31 & 0.26 & 0.11 & 0.03 & 13.00 & 0.03 \\
\hline Gravelly coarse sandstone & 2428 & 1.31 & 0.29 & 1.04 & 0.51 & 5.40 & 35.10 & 0.79 \\
\hline Siltstone 1 & 2226 & 1.43 & 0.33 & 1.40 & 0.54 & 6.58 & 30.24 & 0.75 \\
\hline Sandy mudstone 1 & 2228 & 1.18 & 0.31 & 1.04 & 0.45 & 6.90 & 27.64 & 1.39 \\
\hline Coarse sandstone & 2224 & 1.79 & 0.31 & 1.57 & 0.68 & 8.83 & 25.89 & 1.81 \\
\hline Medium sandstone & 2347 & 6.37 & 0.29 & 5.06 & 2.47 & 14.80 & 30.75 & 3.16 \\
\hline Fine sandstone 1 & 2329 & 6.98 & 0.31 & 6.12 & 2.66 & 14.60 & 30.00 & 3.28 \\
\hline Sandy mudstone 2 & 2322 & 7.06 & 0.29 & 5.60 & 2.74 & 11.10 & 33.27 & 1.35 \\
\hline 22\# coal seam & 1400 & 4.08 & 0.28 & 3.09 & 1.59 & 1.13 & 25.00 & 0.82 \\
\hline Fine sandstone 2 & 2177 & 6.71 & 0.31 & 5.89 & 2.56 & 10.80 & 35.60 & 1.82 \\
\hline Sandy mudstone 3 & 2351 & 9.44 & 0.25 & 6.29 & 3.78 & 23.03 & 28.07 & 5.08 \\
\hline 42\# up coal seam & 1320 & 4.62 & 0.31 & 4.05 & 1.76 & 4.21 & 26.10 & 0.55 \\
\hline Fine sandstone 3 & 2318 & 7.80 & 0.31 & 6.84 & 2.98 & 18.20 & 32.25 & 4.24 \\
\hline Sandy mudstone 4 & 2383 & 10.48 & 0.22 & 6.24 & 4.30 & 24.50 & 26.50 & 5.07 \\
\hline Siltstone 2 & 2334 & 8.86 & 0.30 & 7.38 & 3.41 & 17.65 & 31.05 & 3.45 \\
\hline
\end{tabular}

TABLE 5: Mining height and strength coefficient of the roof.

\begin{tabular}{|c|c|c|c|c|c|}
\hline Lithology & $\sigma_{c}(\mathrm{MPa})$ & $c_{1}$ & $c_{2}$ & $c_{3}$ & $c_{4}$ \\
\hline Hard rock strata & $>40$ & 2.1 & 16 & 1.2 & 2 \\
\hline Medium-hard strata & $20-40$ & 4.7 & 19 & 1.6 & 3.6 \\
\hline Soft strata & $<20$ & 6.2 & 32 & 3.1 & 5 \\
\hline
\end{tabular}

TABLE 6: Mechanical parameters of the rock mass in the caving zone.

\begin{tabular}{lcccccc}
\hline Lithology & $K(\mathrm{GPa})$ & $G(\mathrm{GPa})$ & $\gamma\left(\mathrm{kg} \cdot \mathrm{m}^{-3}\right)$ & $C(\mathrm{MPa})$ & $\varphi\left({ }^{\circ}\right)$ & $\sigma_{t m}(\mathrm{MPa})$ \\
\hline 22\# roof & 14.08 & 10.56 & 1800 & 0.001 & 35 & 0 \\
42\# roof & 9.56 & 7.17 & 1900 & 0.001 & 40 & 0 \\
\hline
\end{tabular}

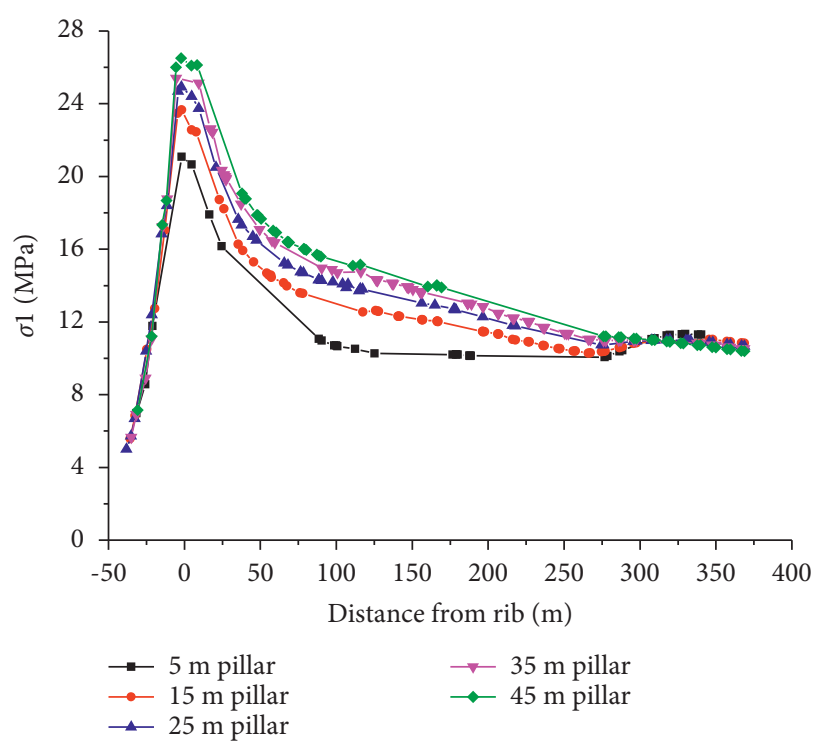

(a)

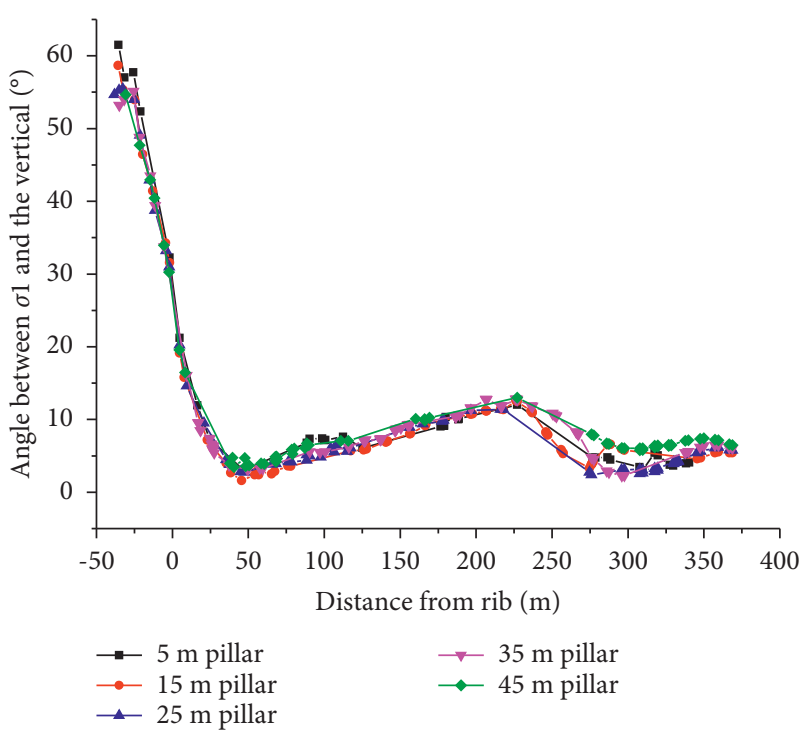

(b)

Figure 7: Continued. 


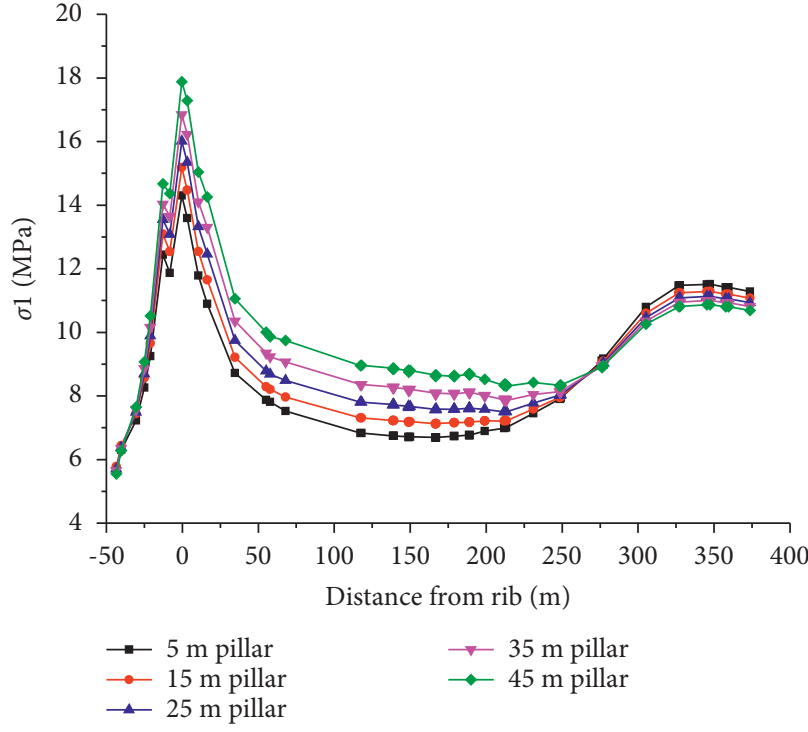

(c)

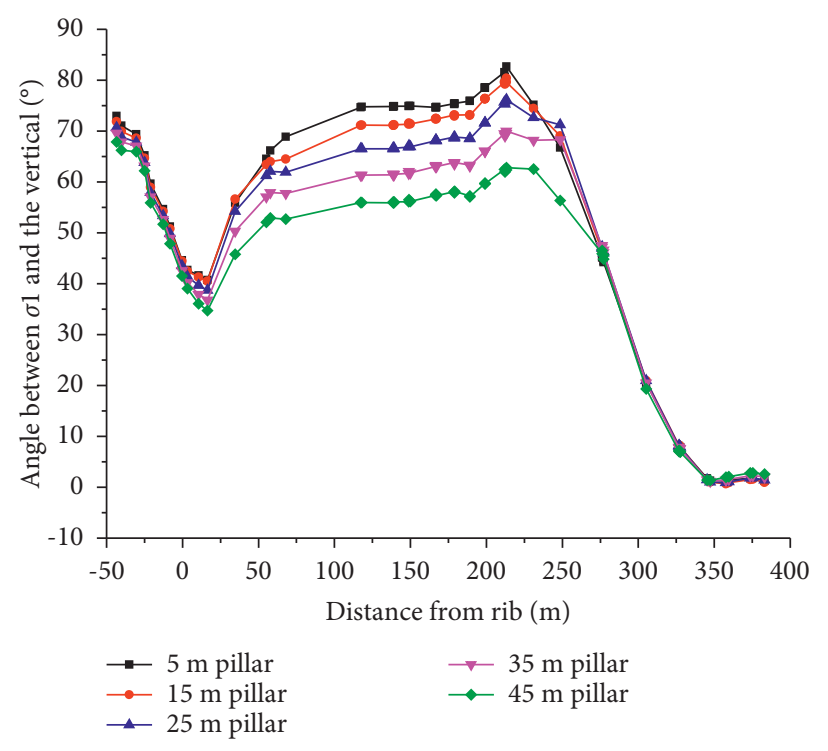

(d)

FIgURE 7: Distribution of principal stress on the main roof strike line. (a) Value of $\sigma 1$ under the pillar. (b) Direction of $\sigma 1$ under the pillar. (c) Value of $\sigma 1$ under the gob. (d) Direction of $\sigma 1$ under the gob.

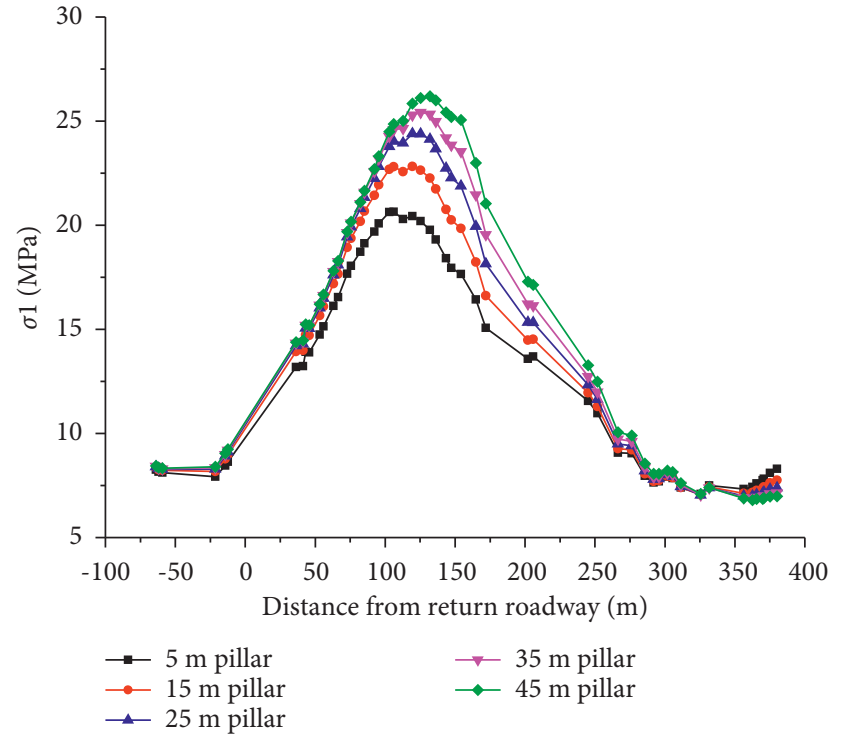

(a)

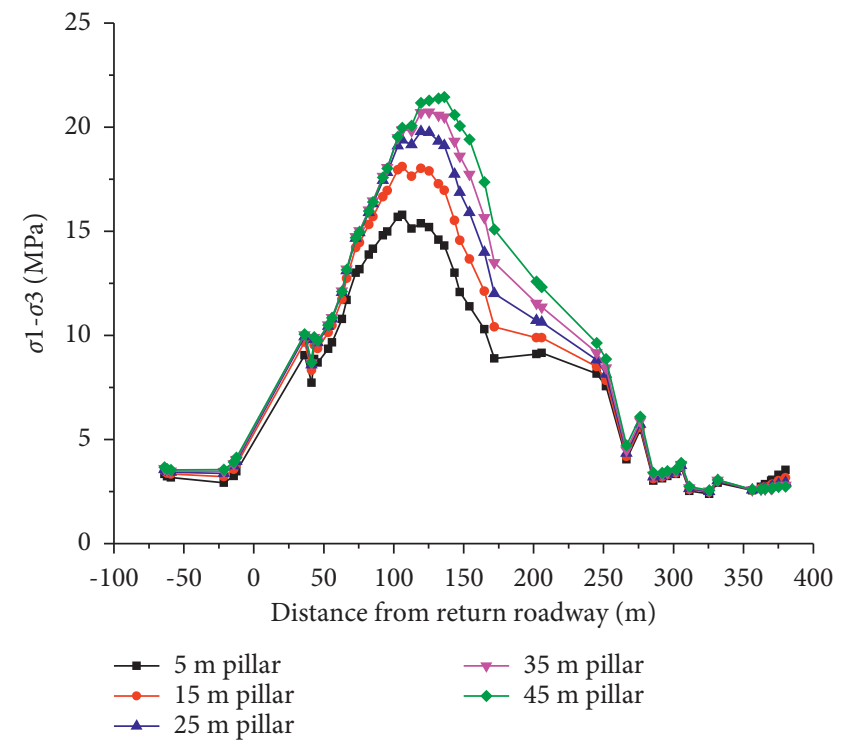

(b)

Figure 8: Distribution of principal stress on the main roof trend line: (a) $\sigma_{1}$ and (b) $\sigma_{1}-\sigma_{3}$.

tensile stress reaches the tensile strength of the roof, and the microcracks in the top coal expand. The expansion of the roof (top coal) cracks can be attributed to the principal stress rotation, the increase in $\sigma_{1}$, and the decrease in $\sigma_{3}$.

4.2.2. Maximum Principal Stress and Deviator Stress in the Inclined Direction. The principal stress distribution of the main roof has a "single-peak" shape (Figure 8) along the inclined direction and $5 \mathrm{~m}$ in front of the rib with high values under the pillar and low values on both sides. With an increase in the pillar width, the peak coefficients of $\sigma_{1}$ increase, the range of increase reduces, and the severe influence range increases. The principal stress peak coefficients are $1.91,2.11,2.26,2.35$, and 2.43, respectively, under different pillar widths of $5 \mathrm{~m}, 15 \mathrm{~m}, 25 \mathrm{~m}, 35 \mathrm{~m}$, and $45 \mathrm{~m}$, and the severe influence range is between 100 and $150 \mathrm{~m}$. Both sides of the working face are affected by the overlying pillar. Although the principal stress increases with an increase in the pillar width, the increase is much smaller than that under the pillar. The $\sigma_{1}$ of the main roof on the strike survey line under the pillar is 1.5 times that under the gob. Similar to the 
$\sigma_{1}$ distribution, the deviator stress on inclined direction also presents a "single-peak" shape, with peak values of 15.8, 18.1, $19.8,20.7$, and $21.4 \mathrm{MPa}$, respectively, under different pillar widths of $5 \mathrm{~m}, 15 \mathrm{~m}, 25 \mathrm{~m}, 35 \mathrm{~m}$, and $45 \mathrm{~m}$.

The deviator stress is the largest within the severe influence range of the pillar and fluctuates significantly. The main roof in the front of the rib breaks under tensile stress because of considerable accumulated strain energy, which transforms into the fracture surface energy and the initial velocity of the fractured rock block, resulting in an impact load. Roof fracture and instability can cause a dynamic catastrophe of the working face due to the combined dynamic and static load.

\section{Conclusion}

The strength-stress ratio method was used to establish the evaluation index for the stress state of the mine rock mass based on the in situ stress measurement through Kaiser effect and the generalized Hoek-Brown rock mass strength criterion, and a preliminary engineering verification was carried out. A refined geological model for the stratum occurrence conditions in the Burtai mine was established with 42 \# coal seam mining combined with the measured in situ stress regression model. The roof stress field of the working face under repeated mining conditions is studied, and the main conclusions are as follows:

(1) An evaluation index of the rock mass stress state for an underground coal mine was established using the strength-stress ratio. It corresponds to high in situ stress state for $\sigma_{c m} / \sigma_{1 m}<1.4$, medium in situ stress state for $1.4<\sigma_{c m} / \sigma_{1 m}<3.6$, and low in situ stress state for $\sigma_{c m} / \sigma_{1 m}>3.6$.

(2) The index is applied in the Burtai mine and classifies it as a medium-high in situ stress field, which is in agreement with the on-site situation, establishing the reliability of the index.

(3) The value and direction of the main roof $\sigma_{1}$ within the range of the front abutment pressure under the pillar and gob vary significantly because of the mining of the overlying coal seam. The value of $\sigma_{1}$ under the pillar along the main roof strike direction is 1.5 times that under the gob, and the $\sigma_{1}$ direction under the pillar is deflected by $5^{\circ}$, which is $30^{\circ}$ smaller than that under the gob. The rotation of principal stress direction, the increase in $\sigma_{1}$, and the decrease in $\sigma_{3}$ can cause the expansion of the roof (top coal) cracks.

\section{Data Availability}

The datasets used during the study are available from the corresponding author upon request.

\section{Conflicts of Interest}

The authors declare no conflicts of interest.

\section{Acknowledgments}

This study was supported by the Fundamental Research Program of Shanxi Province (202101D221355), Project 1331 of Shanxi Province, Graduate Education Innovation Program of Shanxi Province and Shanxi Datong University (2021YJJG306 and 21JG13), the Key Research Development Program of Shanxi Province (201903D121070), the Key Research Development Program of Datong City, Shanxi Province (2019013), Datong Basic Research Project (2019159), and Shanxi Datong University Research Project (2020Q017) and Doctoral Research Startup Fund.

\section{References}

[1] N. Hast, "The state of stress in the upper part of the earth's crust,” Tectonophysics, vol. 8, no. 3, pp. 169-211, 1969.

[2] O. Stephansson, P. Särkkä, and A. Myrvang, "State of stress in Fennoscandia," in Proceedings of the Isrm International Symposium, Cappadocia, Turkey, August 2016.

[3] E. T. Brown and E. Hoek, "Trends in relationships between measured in-situ stresses and depth," International Journal of Rock Mechanics and Mining Science \& Geomechanics Abstracts, vol. 15, no. 4, pp. 211-215, 1978.

[4] B. C. Haimson, "Near-surface and deep hydrofracturing stress measurements in the Waterloo quartzite," International Journal of Rock Mechanics and Mining Science \& Geomechanics Abstracts, vol. 17, no. 2, pp. 81-88, 1980.

[5] P. R. Sheorey, "A theory for in Situ stresses in isotropic and transverseley isotropic rock," International Journal of Rock Mechanics and Mining Science \& Geomechanics Abstracts, vol. 31, no. 1, pp. 23-34, 1994.

[6] M. L. Zoback, "First-and second-order patterns of stress in the lithosphere: the World Stress Map Project," Journal of Geophysical Research Solid Earth, vol. 97, no. B8, pp. 11,70311,728, 1992.

[7] S. X. Yang, Study on the Distribution Characteristics of Crustal Stress Field in Chinese Mainland, Beijing Jiaotong University, Beijing, China, 2013.

[8] F. Jing, Research on the Distribution Rule of the Shallow Crustal Geostress Field in the China Mainland and Engineering Disturbance Characteristics, Graduate School of Chinese Academy of Sciences (Wuhan Institute of Geotechnical Mechanics), Wuhan, China, 2009.

[9] C. J. Feng, Study on the Present in Situ Stress Field beneath the Capital Circle Region, Chinese Academy of Geological Sciences, Beijing, China, 2014.

[10] H. P. Kang, J. Ling, and L. X. Yan, "Study on distribution characteristics of underground in-situ stress field in Shanxi coal mining area," Chinese Journal of Geophysics, vol. 52, no. 7, pp. 1782-1792, 2009.

[11] H. C. Zhu and Z. Y. Tao, "In situ stress distribution in different rocks," Acta Seismologica Sinica, vol. 16, no. 1, pp. 49-63, 1994.

[12] D. A. Zhao, Z. M. Chen, and X. L. Cai, "Statistical analysis of distribution law of in-situ stress field in China," Chinese," Journal of Rock Mechanics and Engineering, vol. 26, no. 6, pp. 1265-1271, 2007.

[13] H. P. Kang, B. D. Yi, and F. Q. Gao, "Underground geostress database and geostress distribution law of coal mines in China," Journal of China Coal Society, vol. 44, no. 1, pp. 23-33, 2019. 
[14] D. H. Yang, Research on In-Situ Stress Measurement Method and Application Based on Kaiser Effect of Borehole Core, China University of mining and Technology, Beijing, China, 2019.

[15] X. F. Yu, Y. R. Deng, and H. H. Liu, Stability Analysis of Surrounding Rock in Underground Engineering, Coal Industry Press, Beijing, China, 1983.

[16] L. S. Xu, B. M. Tang, and C. C. Mu, "Research status of problems related to high ground stress and rockburst," Technology of Highway and Transport, vol. 4, no. 12, pp. 48-51, 2002.

[17] C. H. Wang, Q. L. Guo, and L. Jia, "Theoretical analysis of high stress criterion based on Hoek Brown strength criterion," Progress in Earthquake Sciences, vol. 32, no. 6, pp. 3325-3332, 2012.

[18] D. Yang, Y. Zhao, Z. Ning, Z. Lv, and H. Luo, “Application and development of an environmentally friendly blast hole plug for underground coal mines," Shock and Vibration, vol. 2018, pp. 1-12, Article ID 6964386, 2018.

[19] Q. Wu, X. Li, L. Weng, Q. Li, Y. Zhu, and R. Luo, "Experimental investigation of the dynamic response of prestressed rockbolt by using an SHPB-based rockbolt test system," Tunnelling and Underground Space Technology, vol. 93, Article ID 103088, 2019.

[20] Q. Wu, L. Chen, B. Shen, B. Dlamini, S. Li, and Y. Zhu, "Experimental investigation on rockbolt performance under the tension load," Rock Mechanics and Rock Engineering, vol. 52, no. 11, pp. 4605-4618, 2019.

[21] T. Zhou, J. Zhu, and H. Xie, "Mechanical and volumetric fracturing behaviour of three-dimensional printing rock-like samples under dynamic loading," Rock Mechanics and Rock Engineering, vol. 53, no. 6, pp. 2855-2864, 2020.

[22] T. Zhou, J. B. Zhu, Y. Ju, and H. P. Xie, "Volumetric fracturing behavior of 3D printed artificial rocks containing single and double 3D internal flaws under static uniaxial compression," Engineering Fracture Mechanics, vol. 205, pp. 190-204, 2019.

[23] D. H. Yang, Y. X. Zhao, and C. Zhang, "Experimental study on the influence of cyclic loading on Kaiser effect of sedimentary rocks," Chinese Journal of Rock Mechanics and Engineering, vol. 37, no. 12, pp. 2697-2708, 2018.

[24] D. H. Yang, Z. X. Ning, and Y. M. Li, "In situ stress measurement and analysis of the stress accumulation levels in coal mines in the northern Ordos Basin, China," International Journal of Coal Science \& Technology, vol. 4, 2021.

[25] D. U. Deere, "Technical description of rock cores for engineering purposes," Rock Mechanics and Engineering Geology, vol. 1, no. 1, pp. 16-22, 1964.

[26] Z. T. Bieniawski, "Geomechanics classification of rock masses and its application in tunnelling," in Proceedings of the $3 \mathrm{rd}$ Congress of International Society Rock Mechanics, Denver, CO, USA, September 1974.

[27] N. Barton, R. Lien, and J. Lunde, "Engineering classification of rock masses for the design of tunnel support," Rock Mechanics Felsmechanik Mcanique des Roches, vol. 6, no. 4, pp. 189-236, 1974.

[28] E. Hoek and E. T. Brown, Underground Excavations in Rock, Institution Mining and Metallurgy, London, UK, 1980.

[29] E. Hoek, C. Carranza-Torres, and B. Corkum, "Hoek-Brown failure criterion-2002 edition," in Proceedings of the Fifth North American Rock Mechanics Symposium, Toronto, Canada, July 2002.

[30] E. Hoek and E. T. Brown, "Practical estimates of rock mass strength," International Journal of Rock Mechanics and Mining Sciences, vol. 34, no. 8, pp. 1165-1186, 1997.
[31] E. Hoek and E. T. Brown, "The Hoek-Brown failure criterion and GSI-2018 edition," Joumal of Rock Mechanics and Geotechnical Engineering, vol. 11, no. 3, pp. 445-463, 2019.

[32] Y. H. Song and L. Cong, "Estimation of deformation modulus and disturbance coefficient of rock mass based on GSI," Journal of Basic Science and Engineering, vol. 22, no. 1, pp. 27-34, 2014.

[33] M. G. Qian, P. W. Shi, and J. L. Xu, Mining Pressure and Strata Control, China University of mining and Technology Press, Xuzhou, China, 2010.

[34] H. M. Li, H. G. Li, and S. S. Peng, Physical and Mechanical Properties of Rocks in Shendong Mining Area, Science Press, Beijing, China, 2018.

[35] M. Salamon, "Mechanism of caving in longwall coal mining," in Proceedings of the 31st US Symposium of Rock Mechanics, pp. 161-168, Golden, CO, USA, June 1990.

[36] L. S. Jiang, Q. S. Wu, and X. Y. Li, "Study on coupling analysis method of mining stress and compaction bearing capacity of goaf," Journal of China Coal Society, vol. 8, pp. 1951-1959, 2017.

[37] H. Yavuz, "An estimation method for cover pressure re-establishment distance and pressure distribution in the goaf of longwall coal mines," International Journal of Rock Mechanics and Mining Sciences, vol. 41, no. 2, pp. 193-205, 2004.

[38] A. A. Griffith, "The phenomena of rupture and flow in solids," Philosophical Transactions of the Royal Society of London, vol. A221, pp. 163-198, 1921. 